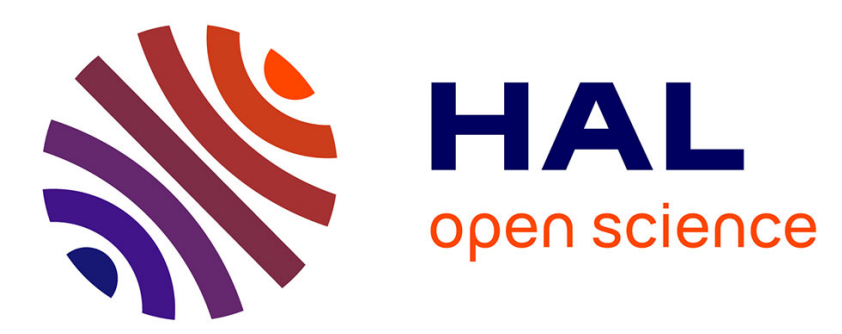

\title{
Study of Bonding Formation between the Filaments of PLA in FFF Process
}

\author{
Achraf Kallel, I. Koutiri, E. Babaeitorkamani, A. Khavandi, M. Tamizifar, \\ Mohammadali Shirinbayan, Abbas Tcharkhtchi
}

\section{- To cite this version:}

Achraf Kallel, I. Koutiri, E. Babaeitorkamani, A. Khavandi, M. Tamizifar, et al.. Study of Bonding Formation between the Filaments of PLA in FFF Process. International Polymer Processing, 2019, 34 (4), pp.434-444. 10.3139/217.3718 . hal-02460959

\section{HAL Id: hal-02460959 \\ https://hal.science/hal-02460959}

Submitted on 30 Jan 2020

HAL is a multi-disciplinary open access archive for the deposit and dissemination of scientific research documents, whether they are published or not. The documents may come from teaching and research institutions in France or abroad, or from public or private research centers.
L'archive ouverte pluridisciplinaire HAL, est destinée au dépôt et à la diffusion de documents scientifiques de niveau recherche, publiés ou non, émanant des établissements d'enseignement et de recherche français ou étrangers, des laboratoires publics ou privés. 


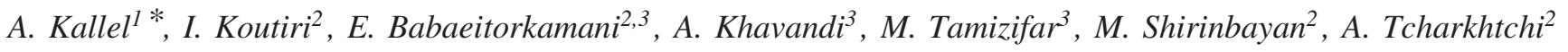 \\ ${ }^{1}$ Léonard de Vinci Pôle Universitaire, Research Center, Paris La Défense, France \\ ${ }^{2}$ Laboratoire PIMM, Arts et Métiers, CNRS, Cnam, HESAM Université, Paris, France \\ ${ }^{3}$ School of Metallurgy and Materials Engineering, Iran University of Science and Technology (IUST), Tehran, Iran
}

\title{
Study of Bonding Formation between the Filaments of PLA in FFF Process
}

\begin{abstract}
Fused filament fabrication $(F F F)$ is an additive manufacturing (AM) process that provides physical objects commonly used for modeling, prototyping and production applications. The major drawback of this process is poor mechanical property due to the porous structure of final parts. This process requires careful management of coalescence phenomenon. In this paper, the major influencing factors during the FFF processing of poly(lactic acid) (PLA) were investigated experimentally and with a numerical model. It has been shown that the polymer temperature has a significant effect on the rheological behavior of PLA, especially on the adhesion of the filaments. An experimental set-up has been placed in the machine to have the cyclic temperature of the filament. A variation of the polymer temperature influences process parameters such as feed rate, temperature of the nozzle and temperature of the platform. The results showed that the amount of polymeric coalescence (neck growth) rises when increasing the feed rate, the nozzle temperature, and the platform temperature. A model to predict the neck growth is proposed. It predicts a lower amount of neck growth value than obtained experimentally. This difference has been explained as the effect of other phenomena, such as polymer relaxation time, pressure of the nozzle and especially cyclic temperature which is not taken into account in the model.
\end{abstract}

\section{Introduction}

Fused deposition modeling (FDM) is an additive manufacturing (AM) process in which a physical object is created directly from a computer-aided design (CAD) model using layer-bylayer deposition of a feedstock plastic filament material extruded through a nozzle. The advantage of FFF includes the ability to produce complex geometrical parts using different materials, especially biomaterials (Chia et al., 2015).

The surface quality has an important influence on the flow field for FFF parts in aerodynamics applications. Porosity can decrease the mechanical properties and consequently the durability and the reliability of the printed part. Improving the

* Mail address: Achraf Kallel, Léonard de Vinci Pôle Universitaire, Research Center, 92916 Paris La Défense, France

E-mail: achraf.kallel@devinci.fr bonds between filaments will increase the density and then improve mechanical properties. The aim of this paper is to study the FFF parameters which influence the filament bonding.

The adhesion between two extruded adjacent filaments may be considered as a well-known coalescence test, the coalescence depending on rheological and physical properties of the material as viscosity, tension surface and relaxation time. The rate of coalescence affects directly the quality of the final products and their mechanical properties (Muller, 2008). The air between the filaments must be pushed out of the part during the deposition of successive layers. The density of the material will increase during this step of densification. Coalescence and densification, also called sintering are the major phenomena in the FFF process. Different authors have studied the sintering phenomenon to predict the degree of bonding between polymer filaments (Bellehumeur et al., 1998; Pokluda et al., 1997).

Li et al. (2003), Bellehumeur et al. (2004), Sun et al. (2008) and Gurrala et al. (2014) investigated on coalescence process and bonding formation of amorphous Acrylonitrile Butadiene Styrene (ABS) filaments during the FFF process. They concluded that under selected conditions, the coalescence phenomenon has a significant effect on the bond formation. They found that there isn't sufficient time for full coalescence of the filaments before complete solidification and hence only partial neck growths appeared.

In the coalescence experiments, the polymer properties are thermally driven and will be changed by changing the temperature of the polymer (Bellehumeur et al., 2004); on the other hand, the FFF process parameters (temperature setting, feed rate and etc) affect the polymer temperature. Sun et al. (2008), Zhang et al. (2017) and Zhou et al. (2017) have experimentally and numerically investigated the thermal behavior of filaments during FFF process by using various polymers, temperature measuring devices, and process parameters. Sun et al. (2008) showed that temperature and variations in the convective conditions within the building chamber have strong effects on the thermal distribution and the overall quality of the bond strength between ABS filaments. Zhang et al. (2017) concluded numerically that temperature settings (temperature of printing nozzle, temperature of heat plate and environment) are crucial factors determining temperature variation. Control of temperature is important to reduce temperature gradient and layer bonding strength. Zhou et al. (2017) indicated that PLA in an hollow piece has the longest diffusion time at high nozzle tem- 
perature, high platform temperature, low printing speed, and high layer thickness. However, despite the studies that have been conducted on the coalescence of amorphous ABS during the FFF process, there are no more studies of the coalescence of semi-crystalline PLA during the FFF process. Studies of the process parameters effect on the degree of polymer bonding are not common. In the present study, PLA, which is a semicrystalline thermoplastic, is used. PLA is a biocompatible and biodegradable polymer (Xiao et al., 2012) and has a large range of uses. The objective of this study is to find the optimal parameters of manufacturing by FFF to obtain a maximal bond between the PLA filaments, which allow better mechanical properties. The bond formation process between two filaments can be modeled through coalescence. Finally, the surface tension was determined with a coalescence test and then used in a modified model to predict the neck growth for FFF process. This paper presents a preliminary study to give first results for further work.

\section{Material and Methods}

\subsection{Materials, 3D Printer and Specimen Preparation}

The white PLA filament is used with a brand name RAL 9003 purchased from CKAB, Paris, France. The features of this PLA are specific gravity of $1.24 \mathrm{~g} / \mathrm{cm}^{3}$ and melt flow rate of $8 \mathrm{~g} / 10 \mathrm{~min}$ at $473 \mathrm{~K}$ using the weight of $2.16 \mathrm{~kg}$. The tensile strength is $22.75 \mathrm{MPa}$ at $296 \mathrm{~K}$ and flexural strength is 436.4 MPa at $296 \mathrm{~K}$. DSC Q10V9.0, Build 275, from TA Instruments, New Castle, UK, was used to determine the melting point, glass transition and crystallization temperature, the degree of crystallinity and the heat capacity. The used polymer was analyzed at from ambient temperature to $453 \mathrm{~K}$ with a heating rate of $5 \mathrm{~K} / \mathrm{min}$. The rheological behavior of the PLA filament was studied using a rheometer MCR 502 from Anton Paar, Istanbul, Turkey. To prepare the required samples for the parallel plate of the rheometer, PLA filaments were cut off into short dimensions by a cutting machine and were dried in a hotbox (Somos RDX2-27 from ProTec Polymer Processing, Bensheim, Germany) at a temperature of $353 \mathrm{~K}$ for two days. The tests were performed at different printing temperatures, under nitrogen atmosphere, in a plateplate configuration with a gap of $1 \mathrm{~mm}$. A scanning electron microscope (4800 SEM, Hitachi, Tokyo, Japan) was used to investigate the value of neck growth between the filaments. Figure 1 shows the results of the DSC test with a heating rate of $5 \mathrm{~K} / \mathrm{min}$ for PLA. The glass transition temperature, the crystallization temperature and the melting temperature of this test, respectively, are reported in Table 1. The PLA can be coalesced between crystallization and melting temperature. This range is the most stable state in the context of the thermodynamics. This meta-stable thermodynamic region of the undercooled polymer melt is called "processing window". According to these results, PLA filaments can coalesce between $373 \mathrm{~K}$ to $423 \mathrm{~K}$.

Figure 2 shows the evolution of PLA viscosity as function of shear rate at different temperatures. In this test, the temperatures are in the range recommended for printing (453 $\mathrm{K}$ and $493 \mathrm{~K})$. The shear rate range varied between 0.01 and $10 \mathrm{~s}^{-1}$.
The shear rate during the process is very low, therefore the melt polymer behaves like a Newtonian fluid. In the literature, was considered that the polymer has a Newtonian behavior to model the 'sintering rate' (Bellehumeur et al., 2004).

By heating the polymer, certain intermolecular bonds (Van der Waals bonds) will be destroyed and the PLA macromolecules get higher mobility; so the melted polymer can flow more easily.

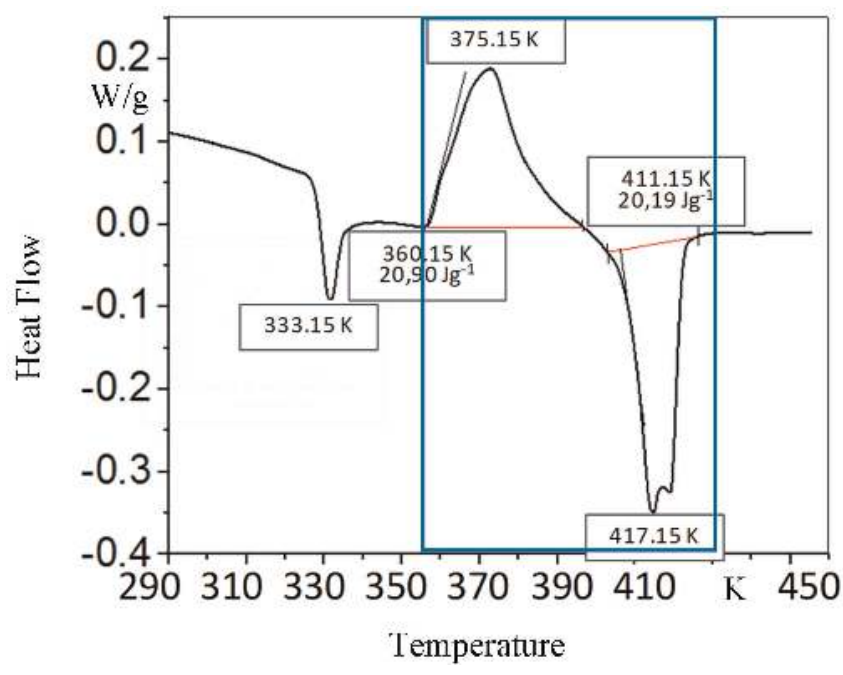

Fig. 1. DSC results of PLA

\begin{tabular}{|c|c|c|}
\hline $\mathrm{T}_{\mathrm{g}}$ & $\mathrm{T}_{\mathrm{c}}$ & $\mathrm{T}_{\mathrm{m}}$ \\
$\mathrm{K}$ & $\mathrm{K}$ & $\mathrm{K}$ \\
\hline 333.15 & 375.15 & 417.15 \\
\hline
\end{tabular}

Table 1. Thermal properties of PLA

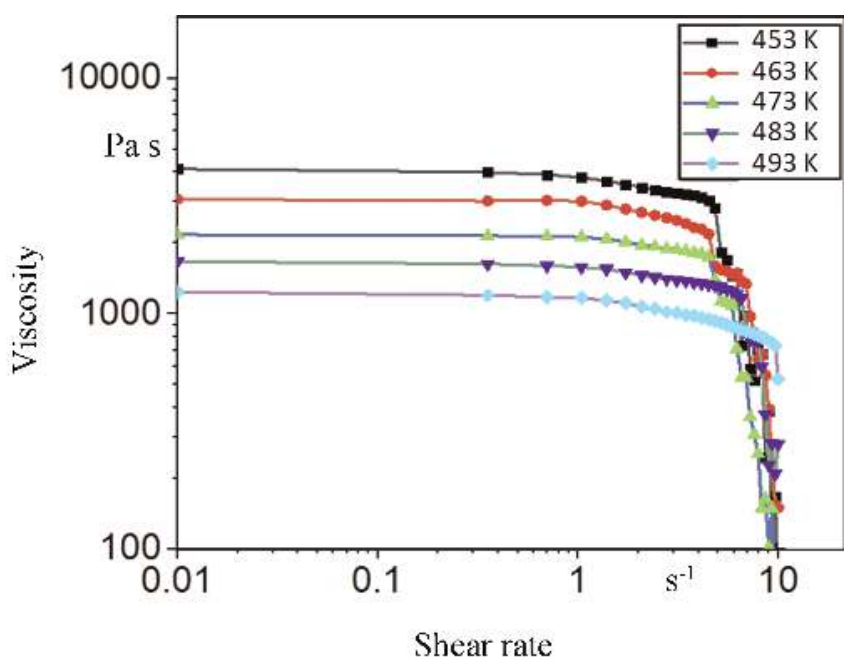

Fig. 2. Evolution of PLA dynamic viscosity versus shear rate at different temperatures 
The values of the Newtonian viscosity at different temperatures are presented in Table 2. By increasing the temperature $43 \mathrm{~K}$, the PLA Newtonian viscosity decreases four times.

One can show using a regression method that the variation of viscosity versus temperature follows an Arrhenius law. In fact, the plot of $\ln (\eta)$ versus $1 / \mathrm{T}$ with the experimental data (Table 2) is a straight line with equation $\ln (\eta)=6.7255(1000 / \mathrm{T})-$ 6.43 and $\mathrm{R}^{2}=0.996$. The slope gives the activation energy $\mathrm{E} / \mathrm{R}=6.7255$ with $\mathrm{E}=56 \mathrm{~K} \mathrm{~J} / \mathrm{mol}$ and $\mathrm{R}=8.314 \mathrm{~J} / \mathrm{mol} \mathrm{K}$.

With this method, we can determine the required viscosity at each temperature to determine the viscosity values in the coalescence model. Temperature has an important effect on viscosity and thus on the bonding of the filament (Sun, 2005). It will be a sensible parameter in the FFF process.

The machine taken for this study is a MakerBot Replicator 2X Experimental 3D Printer (MakerBot Industries, LLC, New York, USA). A sample was drawn in a cuboid form with dimensions of $15 \mathrm{~mm}$ (length) $\times 15 \mathrm{~mm}$ (width) $\times 3 \mathrm{~mm}$ (height). The sample was printed with 5 shells to guarantee that the thermocouple is tied to a unique filament and with a filling of $100 \%$. The fixed parameters of the process are presented in Table 3.

The three most influential manufacturing parameters were closely monitored for their influence on temperature distribution during manufacturing. Table 4 shows the ranges of variation of these parameters.

\subsection{Thermocouple and Measurement Equipment}

The location of the sample on the platform was specified. The thermocouple was placed near the nozzle to measure the polymer temperature when leaving the nozzle and at different print positions. Type K thermocouple (IEC PTFE exposed welded tip) with $0.25 \mathrm{~mm}$ diameter and a sensitivity of approximately $41 \mu \mathrm{V} /{ }^{\circ} \mathrm{C}$, is used. The temperature conversion rate is $100 \mathrm{~ms}$ which is adequate for this application. The distribution of temperature was measured with thermocouples of Datapaq equipment (XDL12 from Fluke Process Instruments, Berlin, Germany). The data was sent to the software to give the curve of temperature versus time. Figure 3 shows the setup. To fix the thermocouple in a reduced area is difficult but possible. The diameter is small. We have done many tests to achieve this experimental study. That's why only one test has been done for each condition.

\subsection{Coalescence Test}

The coalescence experiments are done in different conditions over time to follow the formation of the bonds between the filaments. The test was performed with a hot-stage instrument (T95 controller, Linkam, Waterfield, UK) that is controlled by the Link Sys 32 software (Linkam). The video camera and polarized light optical microscope (BH-2 from Olympus, Tokyo, Japan), equipped with a small heating instrument, are controlled by the video capture software. The tests were performed

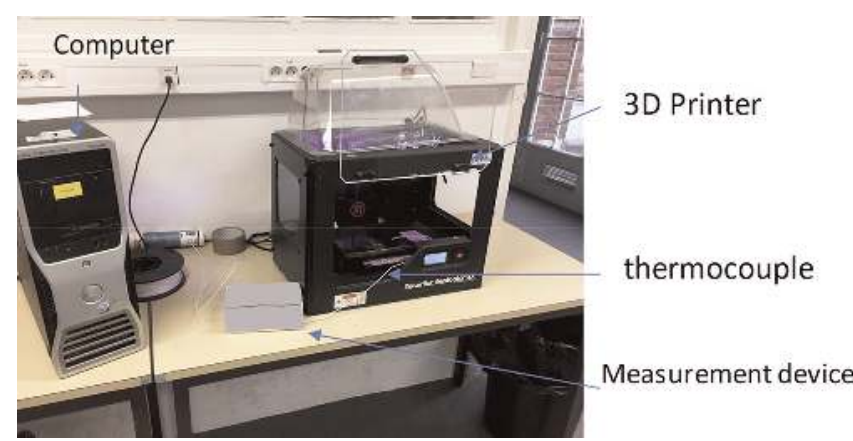

Fig. 3. System setup

\begin{tabular}{|c|c|c|c|c|c|}
\hline Temperature (K) & 453 & 463 & 473 & 483 & 493 \\
\hline Viscosity, $\eta$ (Pa s) & 4130 & 3070 & 2170 & 1670 & 1240 \\
\hline
\end{tabular}

Table 2. Viscosity variation versus temperature

\begin{tabular}{|c|c|c|c|c|c|}
\hline $\begin{array}{c}\text { Layer thickness } \\
\mathrm{mm}\end{array}$ & $\begin{array}{c}\text { Infill } \\
\%\end{array}$ & $\begin{array}{c}\text { Raster angle } \\
\text { ( }\end{array}$ & Orientation & $\begin{array}{c}\mathrm{T}_{\mathrm{e}} \\
\mathrm{K}\end{array}$ & \begin{tabular}{c} 
Number of shell \\
\hline 0.3
\end{tabular} \\
\hline 100 & 0 or 90 & $\mathrm{XYZ}$ & 296 & 1 \\
\hline
\end{tabular}

Table 3. Value of fixed process parameters

\begin{tabular}{|c|c|c|}
\hline $\begin{array}{c}\text { Nozzle temperature } \\
\mathrm{K}\end{array}$ & $\begin{array}{c}\text { Platform temperature } \\
\mathrm{K}\end{array}$ & $\begin{array}{c}\text { Feed rate } \\
\mathrm{mm} / \mathrm{s}\end{array}$ \\
\hline $488-503$ & $313-323$ & $40-60$ \\
\hline
\end{tabular}

Table 4. Value of variable process parameters 
with a thermal set program by setting the temperature to 443 , 453 and $463 \mathrm{~K}$ and the cooling rate at 20 and $25 \mathrm{~K} / \mathrm{min}$.

Each sample consisted of two extruded PLA filaments for the FFF machine with $1.75 \mathrm{~mm}$ of diameter. The coalescence experiments were carried out first under isothermal conditions then with controlled ramp down temperature. The images were analyzed by ImageJ software (NIH, Maryland, USA).

\section{Results and Discussion}

\subsection{FFF Process}

Some tests on the PLA filament behavior were performed to compare the set temperature with the temperature of the material inside the nozzle. In this study, the temperatures were measured before and after extrusion (Fig. 4). The function "load filament" existing in the machine is used for this test. It consists in reaching the value of $488 \mathrm{~K}$ with a rate of $100 \mathrm{~K} / \mathrm{min}$. When the temperature is reached, the extrusion starts with a rate of $10 \mathrm{~mm} / \mathrm{s}$. The material stays in the nozzle about $125 \mathrm{~s}$ before extrusion. A first thermocouple was arranged in the nozzle, outside of the extruder as presented in Fig. 4. The second thermocouple was inserted through the hole of the nozzle in contact with the filament, which is enough to allow the installation, and fixed by the viscosity of the material.

Figure 5 shows the results of both thermocouples. While the temperature of the nozzle remains constant and equal to the software value (Fig. 5 circles), after extruding, the PLA temperature decreases sharply in the filament during the first $10 \mathrm{~s}$ (Fig. 5 squares). It continues cooling slowly until room temperature. The melting polymer inside the nozzle does not reach the required temperature. A gap of $50 \mathrm{~K}$ between the two measured temperatures is observed. This can be explained for different reasons. This phenomenon may be due to latent heat since the material does not stay in the heating zone long enough to accumulate heat and reach the target temperature. In addition, the heat room is continuously supplied with material at room temperature that slows down the temperature of the polymer already inside the extruder.

The temperature for the machine is connected to the nozzle of the extruder. When it is reached, the extruder starts the deposition of the material. Only one test has been done for each condition. That is why a gap of temperature is observed. The temperature record was started right after filament extrusion through the nozzle. The distance between the nozzle and the platform also influences the filament cooling speed. For all the next tests, the same distance value was maintained. Finally, it can be concluded, only for this condition, using a Makerbot machine (MakerBot Industries, New York, USA), that a gap is observed between the temperature in the nozzle and in the material.

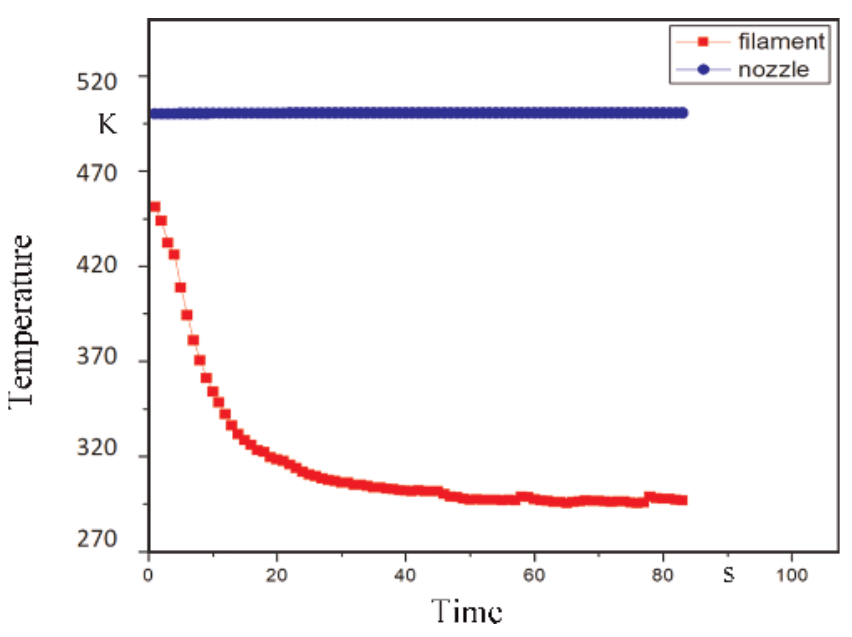

Fig. 5. Temperature of polymer A) in and B) out of the nozzle during time
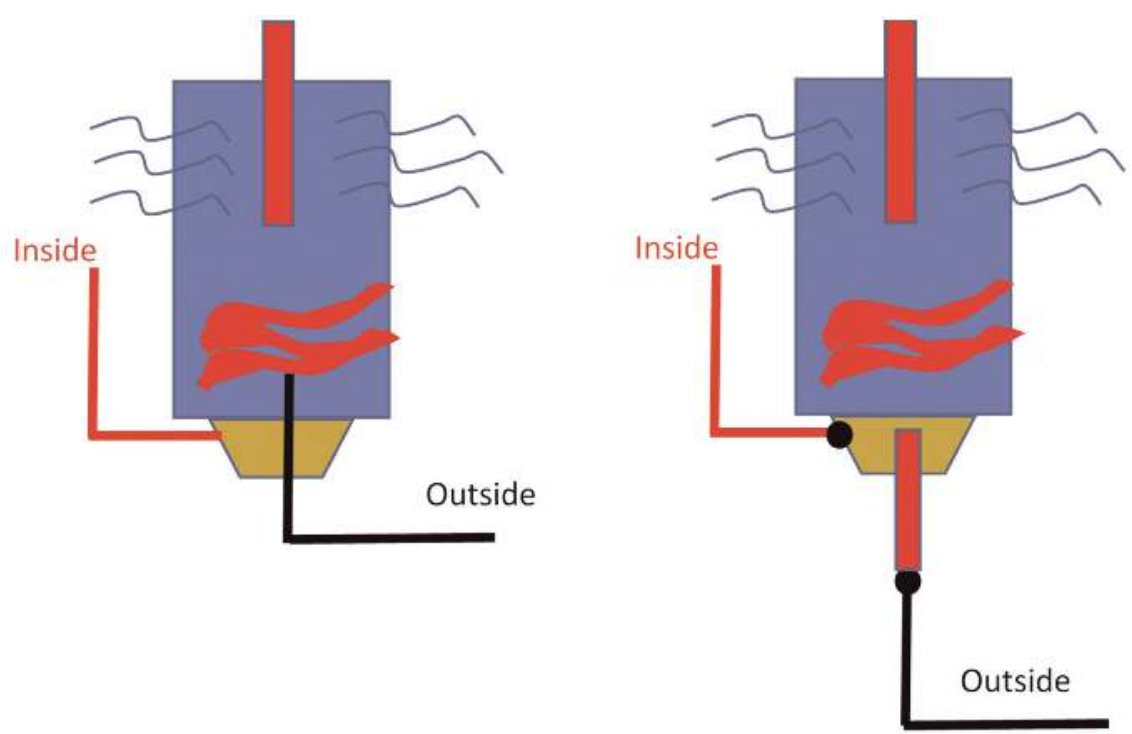

Fig. 4. Thermocouple position (left: before extrusion, right: after extrusion) 


\subsection{Real-Time Temperature Evolution of Filament}

To study the evolution of temperature during FFF process and the effect of different parameters, the following tests were performed (Table 5).

As indicated in Fig. 6, probe number one is placed on the platform to measure the first printed filament temperature. After deposition of five layers, probe number two is inserted in the same position. It should be noted that the position is at more or less one filament. It could be possible that the cooling effect provided by the probe changes the results. Same experimental conditions were applied for all the tests. Also, the volume of the thermocouple is very low compared to the volume of the sample to justify any effect in the results. Only one test has been done in each condition due to the difficulties described.

As an example, Fig. 7 is obtained for condition No. 7 of Table 5, which was performed using two thermocouple probes. The sample was printed with 5 shells to guarantee that the thermocouple is tied to the unique filament and with a filling of $100 \%$. Each recorded temperature peak represents a new-deposited layer.

As can be seen, the temperature of a printed filament changes cyclically due to the reheating by deposition of a new printed filament. The maximum temperature reached by the probe number two, $437 \mathrm{~K}$, is higher than the maximum temperature measured by the probe number one, $410 \mathrm{~K}$. A cyclic variation is observed. Each recorded temperature peak represents a new-deposited layer. Tc and Tm were plotted on each diagram, to compare the temperature evolution of the filament.

To facilitate the interpretation of these results, the upper limit of the cyclic curves is plotted to study the effect of the process parameters on the temperature evolution.

\subsection{Effect of Process Parameters}

\subsubsection{Effect of Nozzle Temperature}

Figure 8 shows the upper limit of temperature evolution in conditions No. 3 and No. 1 of Table 5. As can be seen, the change in the nozzle temperature has no particular effect on the first temperature value for the first layer. However, in the middle layer, this temperature value was shifted. Afterward, the temperature evolution remains the same for both probes. Concern- ing the first layer, the temperature difference between the platform $(313 \mathrm{~K})$ and the nozzle (488 to $503 \mathrm{~K}$ ) is so large that the variation of $15 \mathrm{~K}$ does not affect the change of the first temperature value. This difference tends to decrease along the printing layers. Layer by layer, an accumulation of the heat tends to increase the temperature of the new filament. The gap

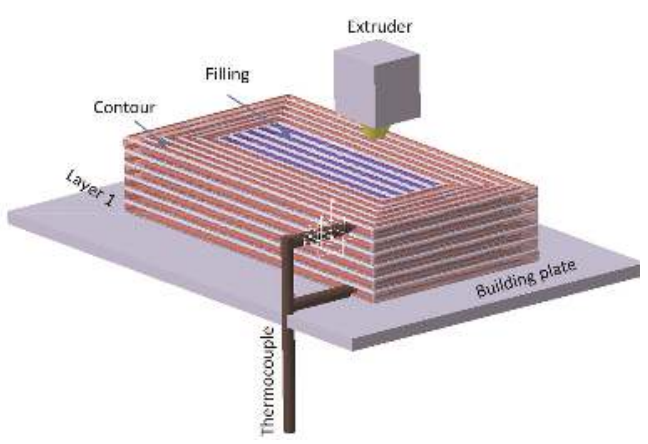

Fig. 6. Position of thermocouple probes in the specimen

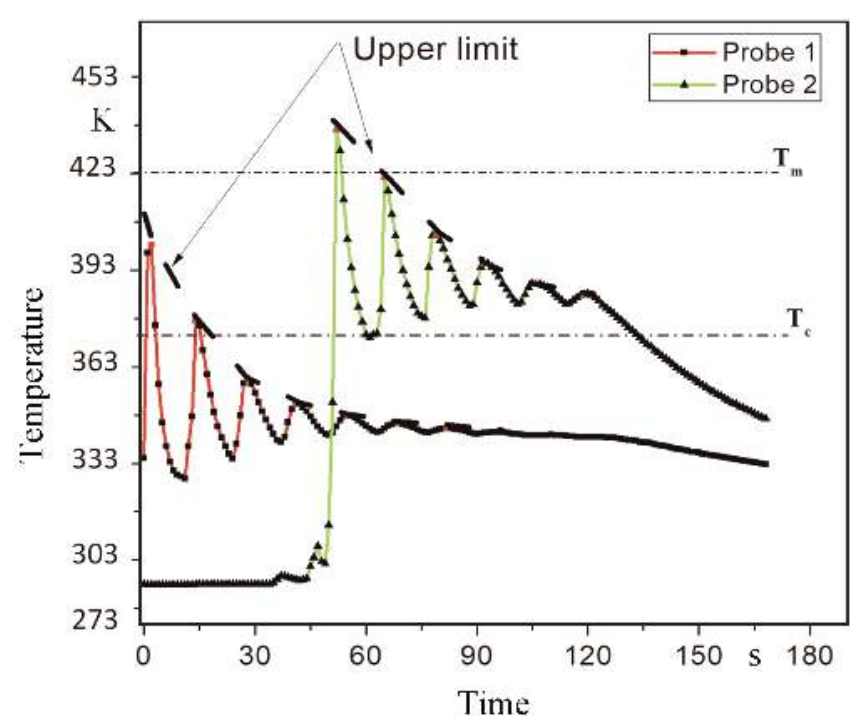

Fig. 7. Temperature during the experimental condition No. 7 of Table 5

\begin{tabular}{|c|c|c|c|}
\hline No. & $\begin{array}{c}\text { Nozzle temperature } \\
\text { K }\end{array}$ & $\begin{array}{c}\text { Feed rate } \\
\mathrm{mm} / \mathrm{s}\end{array}$ & $\begin{array}{c}\text { Platform temperature } \\
\text { K }\end{array}$ \\
\hline 1 & 503 & 60 & 313 \\
2 & 503 & 40 & 313 \\
3 & 488 & 60 & 313 \\
5 & 488 & 40 & 313 \\
6 & 503 & 40 & 333 \\
8 & 503 & 60 & 333 \\
\\
\hline
\end{tabular}

Table 5. Experimental design matrix 
of temperature between the nozzle and the latest filament is significantly reduced. This may explain the change of the first temperature value on probe 2 . While changing the nozzle temperature influences the first layer temperature value, the evolution of the temperature remains similar for the following layers. The environment and external conditions have a greater influence on the evolution of the temperature.

\subsubsection{Effect of Platform Temperature}

Figure 9 shows the effect of the platform temperature on the material. Raising the platform temperature from $488 \mathrm{~K}$ to $503 \mathrm{~K}$

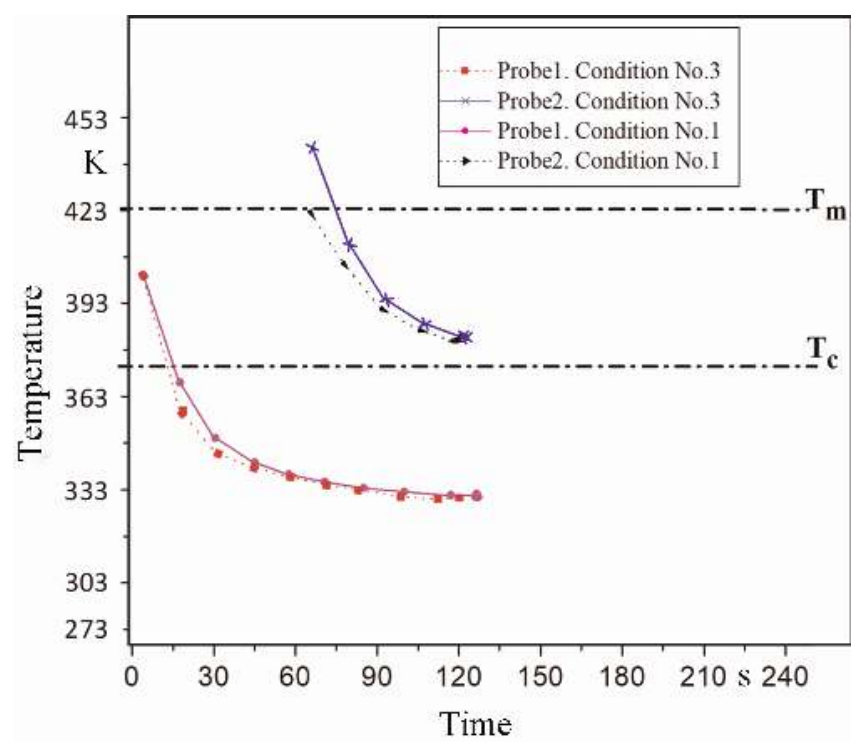

Fig. 8. Effect of nozzle temperature on filament temperature

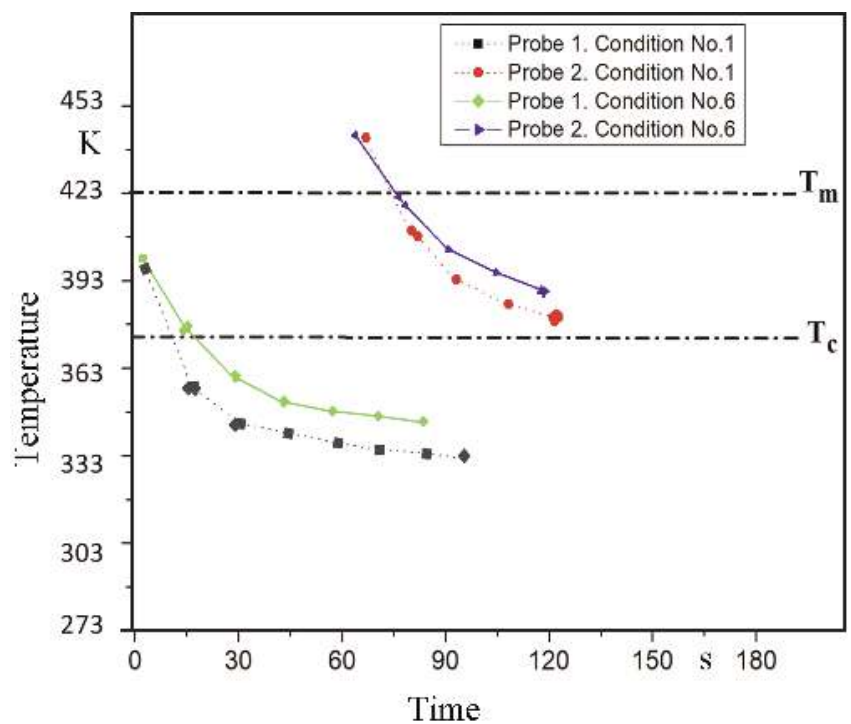

Fig. 9. Effect of platform temperature on peak temperatures measured in $F F F$ will increase the polymer temperature due to the heat transfer to a warmer surface. Of course, since probe number one is close to the platform surface, the change in temperature of the platform has changed the temperature of the initial layers. $15 \mathrm{~K}$ difference in the upper limit temperature are measured on the first layer with probe 1 . However, for probe 2 the difference is less significant. Layers positioned further from the platform have a lower temperature evolution.

\subsubsection{Effect of Feed Rate}

Figure 10 shows the effect of the feed rate on the change in the temperature of the filaments during the process in conditions No. 5 and No. 6 of Table 5. Although the decrease in feed rate has almost no effect on the temperature of the first layer, it varies the temperatures of the middle layers by about $20 \mathrm{~K}$.

When the feed rate decreases from $60 \mathrm{~mm} / \mathrm{s}$ to $40 \mathrm{~mm} / \mathrm{s}$, the necessary printing time for every layer increases. At first, when the printing time increases, the depositing period between each layer increases. Then the cooling time for every layer grows by convection. The difference of the cooling time for the first layers is insignificant with respect to the middle layer in which the cumulated low temperature between every layer is more important.

Figure 11 shows the effect of feed rate on the bonding formation between the filaments at the platform temperature of $333 \mathrm{~K}$ and nozzle temperature of $503 \mathrm{~K}$. We put the samples from different conditions under brittle failure, and their fracture surface was observed using SEM microscopy. The neck growth is better in the upper layers compared to the lower layers. Better layer formation in the feed rate can be observed at $60 \mathrm{~mm} / \mathrm{s}$ (Fig. 11A) compared with $40 \mathrm{~mm} / \mathrm{s}$ (Fig. 11B).

For the conditions studied, it can be concluded that the temperature of the filament is influenced increasingly by:

- the print speed,

- the platform temperature,

- the nozzle temperature.

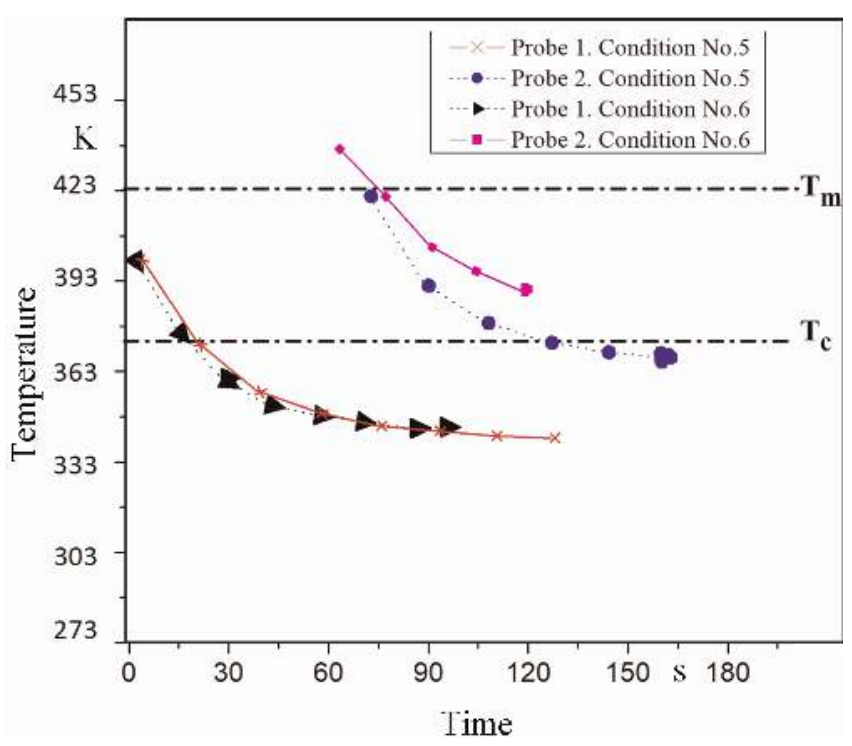

Fig. 10. Effect of feed rate on peak temperatures measured in FFF 
It can be concluded that the temperature is very sensitive and change with the process parameters. Thermal gradient occurs during the fabrication due to the deposition of heated materials, which is rapidly cooled and then reheated by the next filament. The temperature history is significant since its plays an important role in determining the bond formation quality on the interface. The final mechanical properties of the structure are directly connected to the temperature history. Finally, to better understand and quantify the bond formation on the interface, a coalescence test must be done, for simulating and modeling the different observations.

\subsection{Coalescence Test}

\subsubsection{Coalescence Test Results}

Sintering is the major phenomenon that occurs in the FFF process. It begins with the coalescence of two adjacent filaments. The inter-diffusion phenomena of two molten polymeric cylinders in contact is due to the high molecular mobility. Figure 12 shows the images of a cross-section of the material at different stages of coalescence at $443 \mathrm{~K}$. The neck growth is equal to the ratio $\mathrm{x} / \mathrm{a}$ while " $\mathrm{a}$ " is the radius of the filament and " $\mathrm{x}$ " is the radius of the neck. It can be observed that the rate of coalescence is significantly impacted by the thermal conditions of the test (Fig. 13).
This effect can be explained in terms of the influence of the temperature on viscosity and surface tension. By increasing the temperature, the viscosity of the polymer decreases and the surfaces of the filaments become more fluid. In this case, the interdiffusion of the molecular chains in two filaments is easier dur-

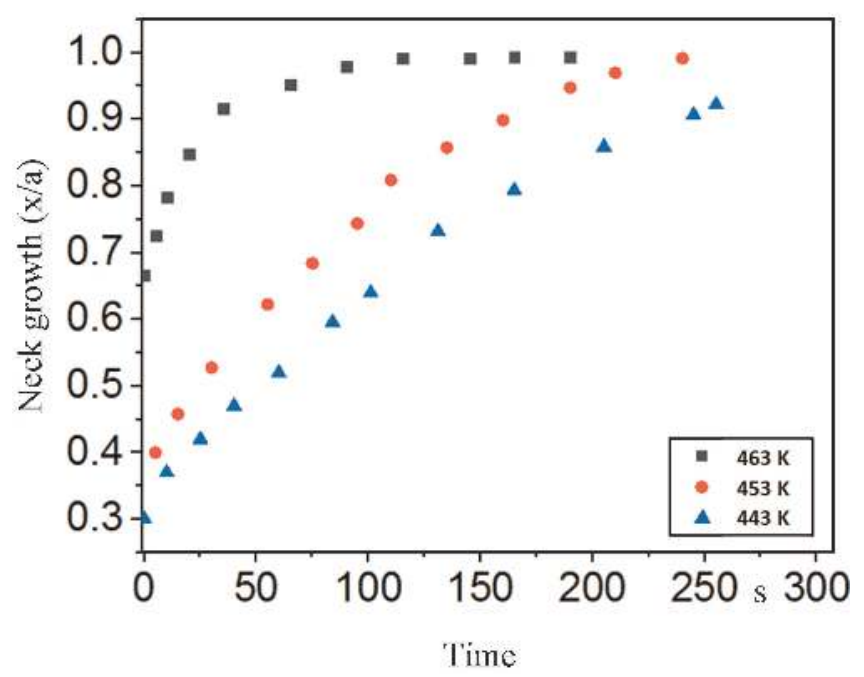

Fig. 13. Neck growth profiles for PLA isothermal coalescence experiments

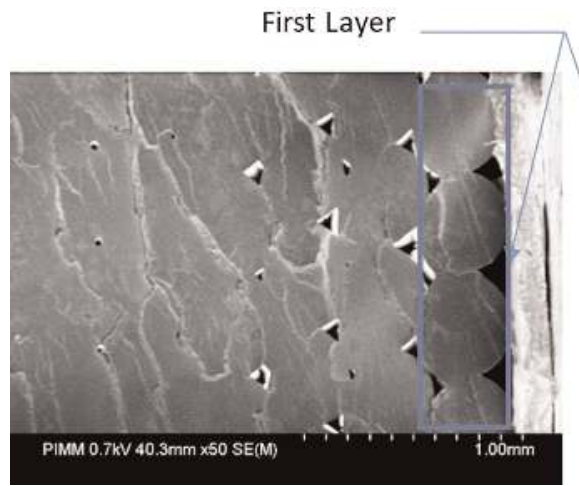

A)

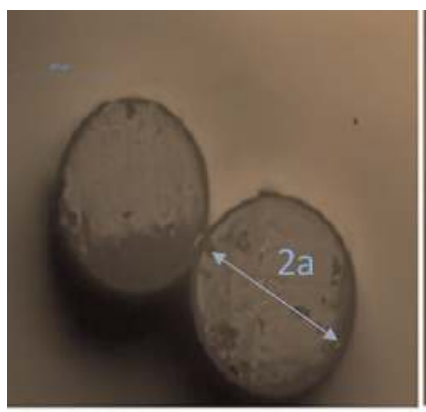

$\mathrm{t}=0 \mathrm{~s}$

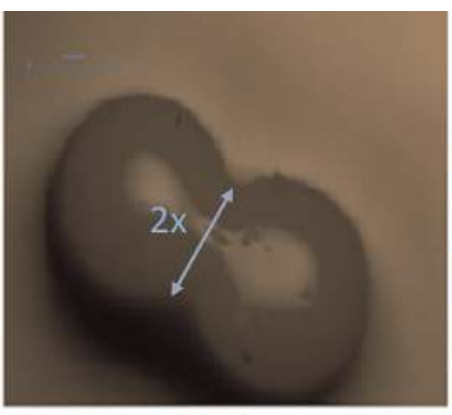

$t=60$ s

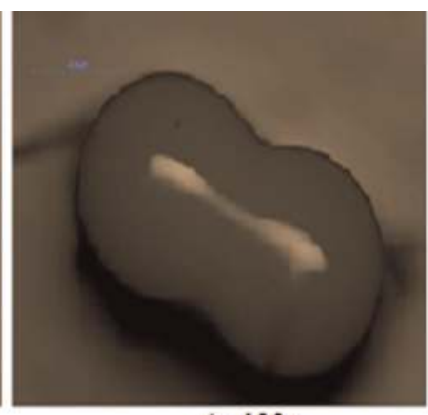

$\mathrm{t}=160 \mathrm{~s}$
Fig. 11. Microscopy observation of conditions A) No. 5, B) No. 6 of Table 5

Fig. 12. Images of coalescence steps of PLA at $443 \mathrm{~K}$ 
ing coalescence. This is influence of temperature on polymers surface tension is not well studied. There are only a few works in this field, which indicate that the surface tension of polymer decreases with an increase in temperature (Sun, 2005).

As shown in Fig. 14, the coalescence rate decreases when increasing the cooling rate.

\subsubsection{Discussion}

Finally, some limits appear to be able to reproduce the same conditions as observed during the process:

- The geometry used for the test is different from that used in the process. The specimen is not a filament with a high length.

- The temperature is the same for the two adjacent grains. The process which extrudes layer by layer gives a different temperature in each layer which is not the case for the sintering test.

- The temperature is not uniform but cyclic during the process. The cooling is not controlled during the coalescence test. It is a significant fact in the case of a visco-elastic material behavior.

\section{Predictive Model}

\subsection{Theoretical Basis and Sintering Modeling}

The sintering occurs through viscous flow and molecular diffusion of the polymer chains. It forms a homogeneous melt from coalescence of two or more particles and densification of them. Between different models proposed to explain this phenomenon, the Pokluda model (Pokluda et al., 1997) is based on Frenkel's model, which can be obtained by writing the equilibrium of the working forces of the surface tension with the viscous forces. In this model, the variation of radius during sintering is considered.

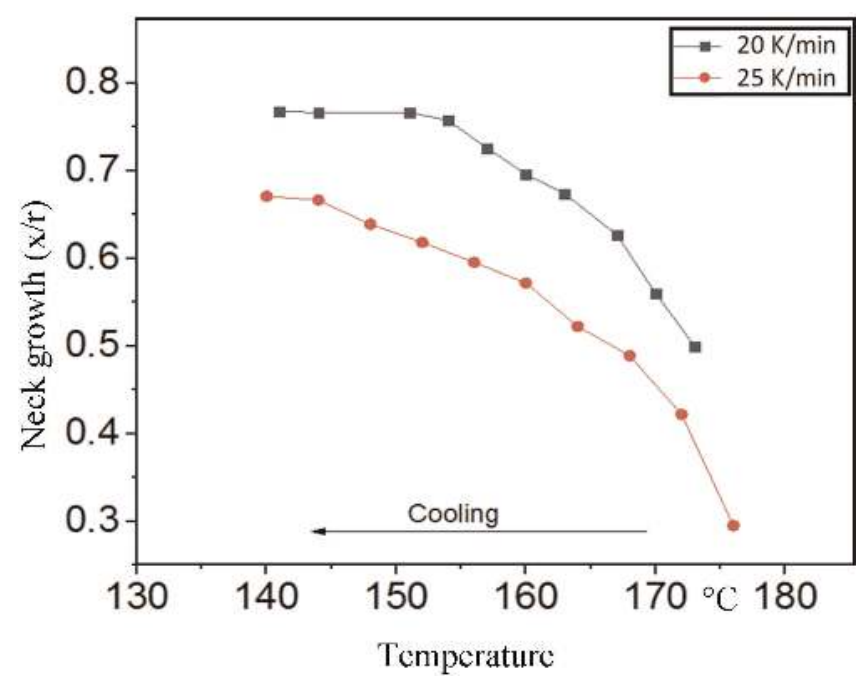

Fig. 14. Effect of cooling rate on the value of coalescence
The work of surface tension is defined as follows:

$\mathrm{W}_{\mathrm{s}}=-\Gamma \frac{\mathrm{ds}}{\mathrm{dt}}=\Gamma \frac{8 \pi \mathrm{a}_{0}^{2} 2^{1 / 3} \cos \theta \sin \theta}{(1+\cos \theta)^{4 / 3}(2-\cos \theta)^{5 / 3}} \frac{\mathrm{d} \theta}{\mathrm{dt}}$,

where $\Gamma$ and s are surface tension and cross-section area of the coalescence system, respectively, $\mathrm{a}_{0}$ is the initial radius of the particle and $\theta$ is the angle of coalescence (Fig. 15). This is given by:

$\theta=\sin ^{-1}\left(\frac{\mathrm{x}}{\mathrm{a}}\right)$.

The work of the viscous forces may be presented as follows:

$\mathrm{W}_{\mathrm{V}}=\iiint_{\mathrm{V}}(\tau: \mathrm{D}) \mathrm{dV}$,

where $\mathrm{V}$ is the volume of the sintering system, $\tau$ and $\mathrm{D}$ are the stress and deformation tensors, respectively. The dissipation energy equation for viscous flow is obtained by using Eq. 3 as follows:

$\mathrm{W}_{\mathrm{V}}=32 \pi \mathrm{a}_{0}^{3} \eta \dot{\varepsilon}^{2}$

with the equality of dissipation energy (Eq. 4) and work of surface tension (Eq. 1), a non-linear differential equation is obtained:

$\frac{\mathrm{d} \theta}{\mathrm{dt}}=2^{-\frac{5}{3}} \frac{\Gamma}{\eta \mathrm{a}_{0}} \frac{\cos \theta \sin \theta(2-\cos \theta)^{\frac{1}{3}}}{(1+\cos \theta)^{\frac{1}{3}}(1-\cos \theta)}$,

where $\eta$ represents the viscosity.

\subsection{Modified Pokluda Model for the FFF Process}

During the FFF process, two adjacent filaments, A and B, are not at the same temperature (Fig. 16). So, they will not have the same viscosity and surface tension. This is a problem for using the model. To solve this problem one can consider an equivalent viscosity, $\bar{\eta}$ and an equivalent surface tension $\bar{\Gamma}$, for two adjacent filaments. A modified mixture law is used (Aid et al., 2017) as follows:

$$
\begin{gathered}
\bar{\eta}=\frac{\eta_{1}+K_{\eta} \eta_{2}}{1+K_{\eta}}, \\
\bar{\Gamma}=\frac{\Gamma_{1}+K_{\Gamma} \Gamma_{2}}{1+K_{\Gamma}},
\end{gathered}
$$
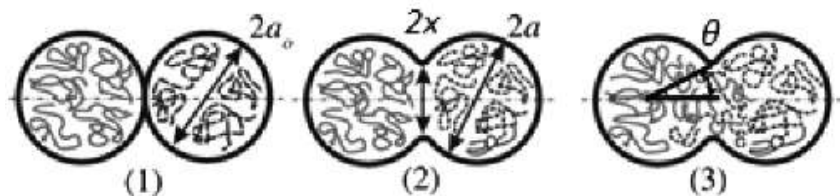

(3)

Time

Fig. 15. Schematic representation of coalescence development (Bellehumeur et al., 2004) 


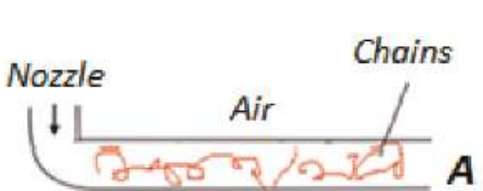

A)

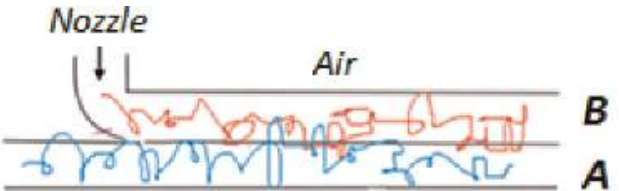

B)
Fig. 16. Schematic of coalescence development, A) first layer, B) second layer where $\eta_{1}$ and $\eta_{2}$ are the viscosity of adjacent filaments 1 and 2 respectively, $\Gamma_{1}$ and $\Gamma_{2}$ are the surface tension of adjacent filament 1 and 2 respectively, and $K_{\eta}$ and $K_{\Gamma}$ are the mixture constants.

So, the Pokluda's model may be modified by replacing the viscosity by the equivalent viscosity and the surface tension by the equivalent surface tension. This modified Pokluda's model considers equivalent properties of the two filaments involved in the coalescence domain of the deposition process.

$\frac{\mathrm{d} \theta}{\mathrm{dt}}=2^{-\frac{5}{3}} \frac{\bar{\Gamma}}{\bar{\eta} \mathrm{a}_{0}} \frac{\cos \theta \sin \theta(2-\cos \theta)^{\frac{1}{3}}}{(1+\cos \theta)^{\frac{1}{3}}(1-\cos \theta)}$.

During coalescence, as the polymers share equally the action of neck formation, the values of $\mathrm{K}_{\eta}$ and $\mathrm{K}_{\Gamma}$ were taken equal to 0.5. To consider the effect of temperature, the following equation was used:

$\eta=\eta_{0} \exp \left(\frac{E}{R T}\right)$

The Arrhenius law (Fulford et al., 2002) is used to consider the effect of temperature on viscosity, where $\mathrm{E}$ is the activation energy and $\mathrm{R}=8.314 \mathrm{~J} \mathrm{~K}^{-1} \mathrm{~mol}^{-1}$. The term of $\eta_{0}$ is a constant. Surface tension is given by:

$\Gamma=\Gamma_{0}\left(1-\frac{\mathrm{T}}{\mathrm{T}_{\mathrm{cr}}}\right)^{\frac{11}{9}}$

Eq. 10 is an empirical relationship between surface tension and temperature, where $T_{c r}$ and $\Gamma_{0}$ are respectively the imaginary critical temperature and the initial surface tension (Du et al. 2007). At last, Eq. 8 is combined with the heat transfer model (Fulford et al., 2002) for FFF:

$\mathrm{T}=\mathrm{T}_{\mathrm{e}}+\left(\mathrm{T}_{\mathrm{p}}-\mathrm{T}_{\mathrm{e}}\right) \exp (-\mathrm{mvt})$,

with:

$\mathrm{m}=\frac{\sqrt{1+4 \alpha \beta}-1}{2 \alpha}, \quad \alpha=\frac{\mathrm{k}}{\rho \mathrm{C}_{\mathrm{p} v}}$ and $\beta=\frac{\mathrm{hP}}{\rho \mathrm{C}_{\mathrm{p}} \mathrm{Av}}, \quad$ where $\mathrm{T}_{\mathrm{e}}, \mathrm{T}_{\mathrm{p}}$, $K, \rho, C_{p}, P, h, A$ and $v$ represent, respectively, the envelop temperature, initial temperature of each filament, thermal conductivity, density, heat capacity, perimeter of filament, thermal conduct conductance, area of filament and feed rate. Table 6 shows the value of some of the above parameters taken from the literature.

\subsection{Model Results}

\subsubsection{Modeling for an Isothermal Filament}

In this section, the results of the Bellehumeur model (Eq. 6) are presented. Physical-rheological properties of PLA are needed for the model as presented in Table 7. Figure 17 shows the numerical results of the coalescence of two PLA filaments in comparison with the experimental coalescence data recorded at $443 \mathrm{~K}$.

\begin{tabular}{|c|c|}
\hline $\begin{array}{c}\text { Viscosity (Lai, 2007) } \\
\text { Pa s }\end{array}$ & $\begin{array}{c}\text { Tension surface (Kino, 2014) } \\
\mathrm{mN} / \mathrm{m}\end{array}$ \\
\hline 5825.49 & 43 \\
\hline
\end{tabular}

Table 7. Physical-rheological properties of PLA at $443 \mathrm{~K}$

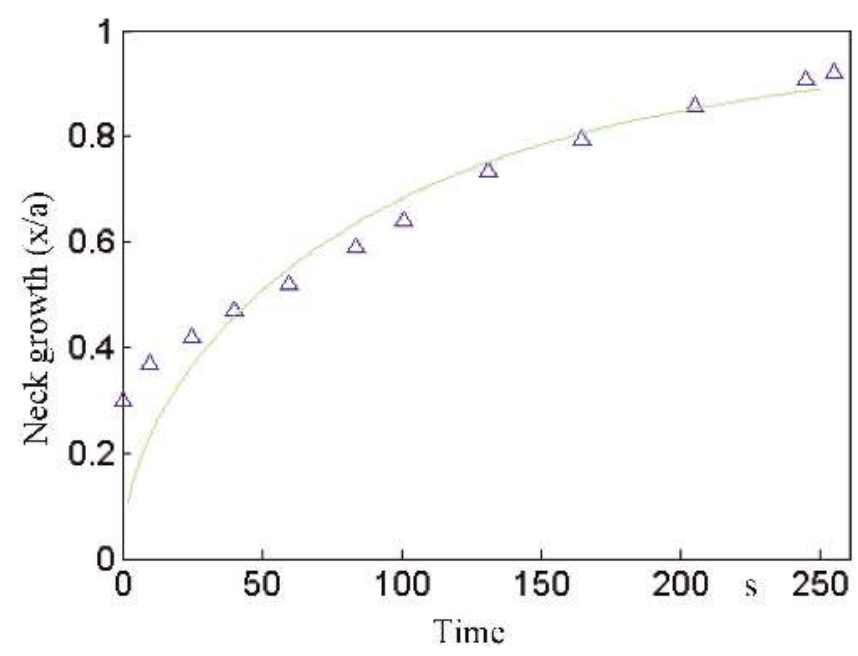

Fig. 17. Experimental results of PLA coalescence at $443 \mathrm{~K}$ and comparison with the numerical model

\begin{tabular}{|c|c|c|c|}
\hline$\Gamma_{0}\left(\mathrm{Nm}^{-1}\right)$ & $\mathrm{T}_{\mathrm{e}}(\mathrm{K})$ & $\mathrm{T}_{\mathrm{cr}}(\mathrm{K})$ & $\eta_{0}(\mathrm{Pas})$ \\
\hline $0.111(\mathrm{Du}$ et al. 2007) & 303 & $845(\mathrm{Du}$ et al. 2007) & $0.00144(\mathrm{Lai} 2007)$ \\
$\mathrm{K}\left(\mathrm{W} \mathrm{m}^{-1} \mathrm{~K}^{-1}\right)$ & $\mathrm{h}\left(\mathrm{W} \mathrm{m}^{-2} \mathrm{~K}^{-1}\right)$ & $\mathrm{C}_{\mathrm{p}}\left(\mathrm{J} \mathrm{mol}^{-1} \mathrm{~K}^{-1}\right)$ & $\rho\left(\mathrm{Kg} \mathrm{m}^{-2}\right)$ \\
$0.111(\mathrm{Lai}, 2007)$ & 88 (Zhou et al., 2017) & 1500.56 (Pyda et al., 2004) & $1145.2(\mathrm{Carlotta}, 2001)$ \\
\hline
\end{tabular}

Table 6. Rheological and thermophysical properties used in numerical model 


\subsubsection{Modified Numerical Model for FFF Process}

The results of the measurement of neck growth level in the first layers and in the middle layers for each condition are presented in Table 8. One notices that the design condition No. 5 of Table 5 presents the highest neck growth value. For this condition, we had the highest platform temperature and the highest feed rate. It should be noted that the value of the neck growth for each layer is derived from the mean value of the filaments neck growth in a layer.

Figure 18 shows the results of solving the differential equation (Eq. 6) in the MATLAB program and the plot obtained from these results for condition No. 5 of Table 5 . As can be seen, the maximum produced coalescence in these conditions is less than the value obtained by the SEM micrographs. Table 8 shows the maximum value for each test condition and model. This phenomenon can have several reasons. In the Lumped capacity (LC) model, the properties of materials such as heat capacity and heat transfer coefficient were considered constant in the model, while in the semi-crystalline polymer heat capacity changes with temperature.

The heat transfer coefficient also varies due to the difference in the type of heat transfer in different areas and during printing. The proposed model for heat transfer must be modified and a more appropriate model presented. As can be observed, the change in the heat transfer coefficient is significantly different in the level of bond between the filaments. Other reasons are due to other factors, such as nozzle pressure on the filament, the weight entered, and the shape change caused by the creep. The difference between the experimental and the model values can have several causes. Materials properties such as heat capacity and heat transfer coefficient were considered in the model as a constant, while in a semi-crystalline polymer heat capacity changes with temperature. This will be a field of investigation and a new challenge to improve the model and make the properties of the polymer change with temperature and, therefore, with time.

The nozzle pressure on the filament causes the polymer to change from the Newtonian to the non-Newtonian state. In this study, the model was based on the Newtonian hypothesis. The higher the thickness for each layer, the greater the pressure applied to the filament. Therefore, the change in thickness will change the state of flow from Newtonian to non-Newtonian and should be considered in future future models. Creep is a no coalescence phenomenon, which can be one of the reasons for the difference between the neck growth obtained from the SEM images and the model.

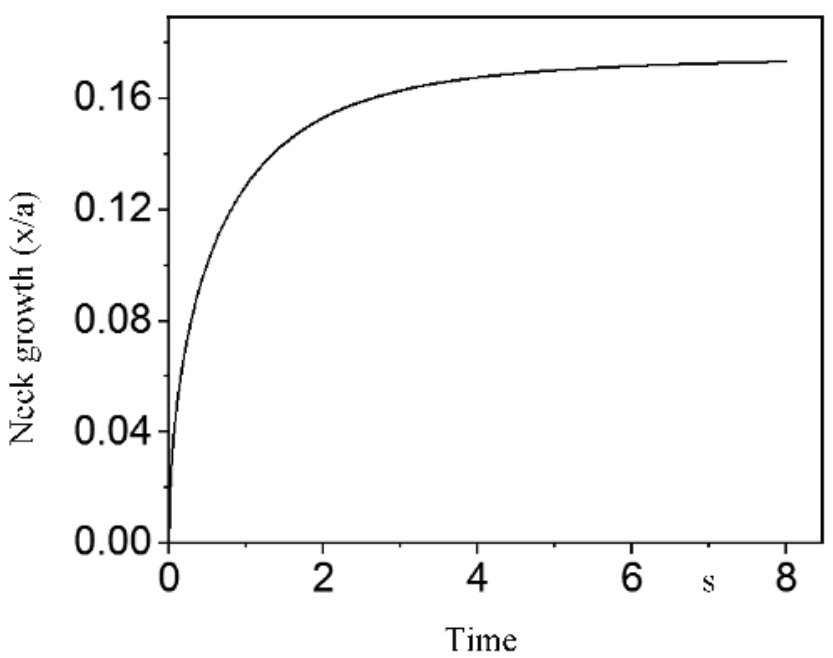

Fig. 18. Result of the modified numerical model for condition No. 5 of Table 5

\section{Conclusions}

In this paper, the physical-rheological phenomenon (coalescence) of PLA during FFF process as investigated experimentally and with a numerical model. The aim of this study was to better understand the behavior of the material during the process, especially the temperature evolution. Based on the results of this study, the following key observations can be made:

- A high difference is observed between the temperature of the filament and the set point.

- The analysis of the temperature of the filament shows a cyclic evolution with different temperatures between layers.

- The influence of process parameters such as feed rate, nozzle temperature and platform temperature on the neck growth of filaments was studied. It appears that the influence of each parameter is different. The temperature of the filament is influenced, increasingly by the print speed, the platform temperature and finally the nozzle temperature, for the range used.

- A coalescence test has been done to observe the neck growth evolution with temperature and time. Some limits appear to reproduce the same conditions as observed during the process. The geometry of the sample, the specimen and the temperature cycle are different. Cooling is not controlled during the coalescence test.

\begin{tabular}{|c|c|c|c|c|c|c|c|c|}
\hline No. & 1 & 2 & 3 & 4 & 5 & 6 & 7 & 8 \\
\hline Experimental & 0.5 & 0.45 & 0.39 & 0.35 & 0.58 & 0.40 & 0.52 \\
Modeling & 0.11 & 0.1 & 0.13 & 0.12 & 0.17 & 0.12 & 0.13 & 0.16 \\
\hline
\end{tabular}

Table 8. Microscopy observation for each condition and comparison with modeling results of the value of neck growth (first layer) 
- A predictive model of the neck growth is proposed. The modified model for sintering had non-isothermal conditions (conditions during the process). It shows a lower amount of neck growth than the experimental data, which can be due to consideration of constant heat capacity, heat transfer coefficient, polymer relaxation time and pressure of the nozzle.

For future work, we suggest to better understand the coalescence phenomenon under pressure. It is also recommended to study the influence of various factors such as the size of the piece, the selected thickness of each layer, and more parameters.

The temperature of the filament does not exceed $443 \mathrm{~K}$ so bonding between filaments is limited. To increase the adhesion between each filament and layer, the temperature must be increased. One way is to increase the temperature in the build chamber.

\section{References}

Aid, S., Eddhahak, A., Ortega, Z., Froelich, D. and Tcharkhtchi, A., "Predictive Coalescence Modeling of Particles from Different Polymers: Application to PVDF and PMMA Pair", J. Mater. Sci., 52, 11725 - 11736 (2017), DOI:10.1007/s1085

Bellehumeur, C., Li, L., Sun, Q. and Gu, P., "Modeling of Bond Formation between Polymer Filaments in the Fused Deposition Modeling Process", J. Manuf. Processes, 6, 170-178 (2004), DOI:10.1016/S1526-6125(04)70071-7

Bellehumeur, C. T., Kontopoulou, M. and Vlachopoulos, J., "The Role of Viscoelasticity in Polymer Sintering", Rheol. Acta, 37, 270-278 (1998), DOI:10.1007/s003970050

Chia, H. N., Wu, B. M., "Recent Advances in 3D Printing of Biomaterials", J. Biological. Eng., 9, 1-14 (2015), PMid:25866560; DOI:10.1186/s13036-015-0001-4

Du, W., Douadji, L., Delmotte, M., Mazabraud, P. and Tcharkhtchi, A., "Modélisation du Mécanisme de Coalescence des Grains de Polymère", SFT Congrès Français de Thermique, Ile des Embiez, France, p. 278-284 (2007)

Fulford, G. R., Broadbridge, P., "Industrial Mathematics Case Studies in the Diffusion of Heat and Matter", $1^{\text {st }}$ Edition, Cambridge University Press, Cambridge (2002), DOI:10.1017/CBO9780511613210

Garlotta, D., "A Literature Review of Poly(lactic acid)", J. Polym. Environ., 9, 63-84 (2001), DOI:10.1023/A:102020082

Gurrala, P. K., Regalla, S. P., "Part Strength Evolution with Bonding between Filaments in Fused Deposition Modelling", Virtual and Phys. Prototyping, 9, 141-149 (2014), DOI:10.1080/17452759.2014.913400

Kino Industry, "Measurement of Surface Tension of PLA for 3D Printer Using Contact Angle Meter SL200 K", Technical Report, Boston, USA (2014)
Lai, J., "Moldflow Material Testing Report MAT2238 - Natureworks PLA", Moldflow Plastics Labs, Victoria, USA (2007)

Li, L., Gu, P., Sun, Q. and Bellehumeur, C., "Modeling of Bond Formation in FDM Process", NAMRC 31st North American Manufacturing Research Conference, Hamilton, Ontario, Canada, p. 219222 (2003)

Muller, J. D., "Etude des Changements de Phase de Polymère dans le Procédéde Rotomoulage: Coalescence et Cristallisation Couplées a la Thermique du Procédé", PhD Thesis, Ecole Doctorale Materiaux de Lyon, Lyon, France (2008)

Pokluda, O., Bellehumeur, C. T., and Vlachopoulos ,J., "A Modification of Frenkel's Model for Sintering", American Inst. Chem. Eng. J., 43, 3253-3256 (1997), DOI:10.1002/aic.690431213

Pyda, M., Bopp, R. C. and Wunderlich, B., "Heat Capacity of Poly (Lactic Acid)", J. Chem. Thermodyn., 36, 731 -742 (2004), DOI:10.1016/j.jct.2004.05.003

Sun, Q., "Bond Formation between Polymer Filaments in Fused Deposition Modeling Process", MSc Thesis, Department of Chemical and Petroleum Engineering, University of Calgary, Calgary, Canada (2005)

Sun, Q., Rizvi, G. M., Bellehumeur, C. T. and Gu, P., "Effect of Processing Conditions on the Bonding Quality of FDM Polymer Filaments," Rapid Prototyping J., 14, $72-80$ (2008), DOI:10.1108/13552540810862028

Xiao, L., Wang, B., Yang, G. and Gauthier, M., "Chapter 11 Poly(lactic acid)-Based Biomaterials: Synthesis, Modification and Applications", in Biomedical Science, Engineering and Technology, Intechopen, London, p. 247-282 (2012), DOI:10.5772/1020

Zhang, J., Zhou, X., Wang, W., and He, Y., "Numerical Investigation of the Influence of Process Conditions on the Temperature Variation in Fused Deposition Modeling", Mater. Des., 130, 59-68 (2017), DOI:10.1016/j.matdes.2017.05.040

Zhou, X., Hsieh, S. and Sun, Y., "Experimental and Numerical Investigation of the Thermal Behaviour of Polylactic Acid during the Fused Deposition Process", Virtual and Phys. Prototyping, 12, $221-233$ (2017), DOI:10.1080/17452759.2017.1317214 